Original Article

\title{
Outcome of the Traumatic Extradural Hematoma on the Basis of Size of Extradural Hematoma
}

\author{
Muhammad Tariq ${ }^{1}$, Mushtaq Ahmad Mian², Muhammad Ali ${ }^{3}$, Shahid Ayub ${ }^{3}$ \\ Waseem Dad Khan ${ }^{1}$, Sohail Daud Khan' ${ }^{1}$, Khial Jalal ${ }^{1}$ \\ ${ }^{1}$ Northwest General Hospital \& Research, ${ }^{2}$ Rehman Medical Institute, Hayatabad, ${ }^{3}$ Hayatabad Medical \\ Complex, Peshawar - Pakistan
}

\section{ABSTRACT}

Objective: This study aimed to determine the outcome of traumatic extradural hematoma and to compare the outcome of small and large size extradural hematoma.

Materials \& Methods: A descriptive case series was carried out in the Department of Neurosurgery, Hayatabad Medical Complex Peshawar for six months and included 188 patients. The detailed history and clinical examinations were noted through a pre-designed proforma. Patients were followed post-operatively till the time of discharge and for either favorable outcome or unfavorable outcome according to the GOS.

Results: $73 \%$ of patients had extradural hematoma volume between $25-50 \mathrm{~mL}$, while $27 \%$ patients had extradural hematoma $>50 \mathrm{~mL}$. $12 \%$ of patients had Glasgow Outcome Score (GOS) scores $1-3$, while $88 \%$ of patients had GOS scores: $4-5$. The mean GOS was 3. Patients with favorable outcomes were $88 \%$ while $12 \%$ had an unfavorable outcome.

Conclusion: The size of the extradural hematoma has a strong correlation with outcome. The greater the size of the hematoma, the poorer the outcome.

Keywords: Epidural Hematoma, Glasgow Outcome Score, Traumatic Brain Injury.

Corresponding Author: Muhammad Tariq

Northwest General Hospital \& Research, Peshawar - Pakistan

Email: tariqbarki2@gmail.com

Date of Submission: 15-04-2021

Date of Revision: 10-06-2021

Date of Online Publishing: 13-06-2021

Date of Print: 30-06-2021

DOI: $10.36552 /$ pjns.v25i2.524

\section{INTRODUCTION}

Traumatic brain injury (TBI) is becoming the most common cause of death and disability worldwide. Currently, the incidence of head injury is 50 per 100,000 population in Pakistan and it is rising rapidly with an increasing trend in the use of motor vehicles and the use of warfare as the current geopolitical situations. ${ }^{1-2}$ Extradural Hematoma $(E D H)$ is one of the most serious neurosurgical emergencies following head injury which is surgically treatable and carries a good 
prognostic outcome after the operation. It could be defined as the accumulation of blood in the space between the skull bone and the underlying dural membrane. EDH occurs in around $1-3 \%$ of patients with head injuries and in $5-15 \%$ of patients with severe head injuries. Its incidence decreases with increasing age and has a male to female ratio in the range of $4: 1$ to $10: 1$ in different studies. Computed tomography (CT) scan is the investigation of choice for diagnosis, management planning, and determining other intracerebral traumatic lesions. ${ }^{3-4} \mathrm{EDH}$ can be fatal rapidly especially if the bleeding vessel is large or if another intracerebral traumatic lesion is associated. $^{5-6}$ Craniotomy has been favored in most studies as a surgical approach due to the wide exposure and being less traumatic in terms of decreased bone loss. In rapidly deteriorating patients with suspected EDH, a CT scan is inappropriate, and a burr hole is placed ipsilateral to the side of pupillary dilatation and contralateral to the side of motor signs. Epidemiologic and hospital-based studies have taken into account the various factors which affect the outcome of patients in surgically operated patients of $\mathrm{EDH} .^{7}$ These factors however have always remained the subject of widespread research in order to improve the various phases of the Neurotrauma patient's endeavor from prehospital rescue to the Neuro-intensive care inside the high dependency unit. ${ }^{8}$ Mushtaq et al studied the outcome of EDH in relation to the hematoma volume showed that outcome in terms of GOS was associated significantly with the volume of hematoma. They categorized $\mathrm{EDH}$ as large volume ( $50 \mathrm{~mL}$ to $100 \mathrm{~mL}$ ) and smaller volume ( 25 $\mathrm{mL}$ to $50 \mathrm{~mL}$ ). In this study, $39.4 \%$ of patients showed favorable outcome in both the smaller volume hematoma group while $39.3 \%$ of favorable outcome in large volume hematoma group. ${ }^{9}$

Head injury can be defined as a change in mental and physical state after a traumatic blow to the head. Consciousness is not always lost. The presenting Glasgow Coma Scale of the patient helps to determine the severity of injury to a large extent. The GCS divides the patients' injury into three categories of severe, moderate, and mild severity. Bleeding can occur inside the calvarium due to direct or counter-coup assault on brain tissue. This gives rise to intracerebral, extradural, subdural or intraventricular types of bleeding. Trauma to the middle meningeal vessels results in extradural hemorrhage while trauma to bridging veins leads to extracerebral, subdural hemorrhage. ${ }^{11-14}$ In the Trauma Coma Data Bank study, the mortality rate was related to hypotension and hypoxia, which occurred secondarily. As a result of expanding hematoma, brain parenchyma suffers from raised intracranial pressure, increased tissue hypoxia, ischemia, neuronal injury, and cellular death. ${ }^{15-16}$ The poor outcome, disability, and death are related to the duration of hypotension and raised ICP. ${ }^{16-17}$ When herniation of the brain occurs due to raised ICP, the pupil dilates on the ipsilateral side. Ptosis or impaired ocular motility occur. Raised ICP also causes $6^{\text {th }}$ cranial nerve (CN) palsy. CNVII palsy results in decreased hearing and often has a fracture of the temporal bone. Sensory neural hearing loss occurs in $20-30 \%$ of cases. ${ }^{18}$ Shearing stresses from an external blow to the skull result in bleeding from the interposed vessels leading to epidural hematomas. ${ }^{19}$ Fractures in adults are very common in head trauma. Arterial and venous insults result in hematoma formation. In cases of venous involvement, the condition has chronicity. Suture lines are adherent to the dura and they limit the extension of an internal bleed, however, epidural hematomas can make exceptions. ${ }^{20}$ The most common vessel involved in the middle meningeal artery (66\%). Assault to the frontal bone damages the anterior ethmoidal artery. Occipital injuries can damage the transverse or the sigmoid sinus. Trauma to the vertex results in superior sagittal sinus bleed. Adult bilateral epidural hematomas are rare $(2-10 \%)$ but are exceedingly rare in 
children..$^{19}$ Intoxication increases the incidence of epidural hematoma. ${ }^{21}$ The raised pressure after an epidural/extradural hematoma invariably causes intracranial hypertension. ${ }^{22}$ Epidural hematomas can also occur in the absence of trauma, for instance, infections, vascular malformations coagulopathies, and metastasis. This current study focused to determine the outcome of traumatic extradural hematoma and to compare the outcome of small and large size extradural hematoma.

\section{MATERIAL AND METHODS}

\section{Study Design \& Setting}

A descriptive case series was conducted at the Department of Neurosurgery, Post Graduate Medical Institute, Hayatabad Medical Complex, Peshawar. The duration of the study was 6 months, from 29-4-2017 to 28-10-2017. Prior ethical approval was taken for this study from IRB. 188 patients included from the emergency or outpatient door (OPD) department as per the selection criteria.

\section{Sample Size \& Technique}

The sample size was 188 using $39.3 \%$ favorable outcome in large volume hematoma group ${ }^{3}, 95 \%$ confidence level, $7 \%$ margin of error from $\mathrm{WHO}$ software. A consecutive non-probability sampling was considered.

\section{Inclusion Criteria}

All patients from both genders aging between 18 - 65 years presenting within 24 hours of traumatic extradural hematoma.

\section{Exclusion Criteria}

Patient with postoperative extradural hematoma, recurrent extradural hematoma or spontaneous extradural hematoma were excluded.

\section{Data Collection}

The detailed history and clinical examinations were noted through a pre-designed proforma. The diagnosis was confirmed using CT of the brain followed by routine investigations. Surgical planning was established with the help of assessment by an experienced Neurosurgeon.

\section{Follow-up}

Patients were followed post-operatively till the time of discharge and assessed by an expert Neurosurgeon in the form of either favorable outcome or unfavorable outcome according to the GOS. In order to deal with the bias, the exclusion criteria were strictly followed.

\section{Data Analysis}

Descriptive statistics, frequencies, related percentage and data stratifications were calculated in SPSS version 25. Chi-square tests were applied on post-stratified data to observe the significance of difference. A $p$ value $<0.050$ was taken as significant.

\section{RESULTS}

\section{Age Distribution}

60 (32\%) patients were between $20-30$ years, 53 (28\%) patients were between $31-40$ years, 41 (22\%) patients were between $41-50$ years, and $34(18 \%)$ patients were between $51-60$ years. The mean age of the patients was $33 \pm 2.71$ years.

\section{Gender Distribution}

141 (75\%) patients were male, 47 (25\%) patients were female.

\section{Volume Extradural Hematoma}

Among 188 patients, the 137 (73\%) patients had extradural hematoma volume of $25-50 \mathrm{~mL}$, while 
51 (27\%) patients had extradural hematoma volume of $>50 \mathrm{~mL}$ (Table 1).

\section{GOS Scores}

Among 188 patients, the 23 (12\%) patients had GOS scores: 1 - 3, while 165 (88\%) patients had GOS scores: $4-5$. Mean GOS was $3 \pm 1.34$ (Table 2).

Table 1: Hematoma Volume ( $N=188)$.

\begin{tabular}{|lcc|} 
Hematoma Volume & Frequency & Percentage \\
Small $(25-50 \mathrm{~mL})$ & 137 & $73 \%$ \\
Large $(>50 \mathrm{~mL})$ & 51 & $27 \%$ \\
\multicolumn{1}{c}{ Total } & $\mathbf{1 8 8}$ & $\mathbf{1 0 0 \%}$ \\
Mean Hematoma Volume: $41 \pm 11.83 \mathrm{~mL}$ & \\
\hline
\end{tabular}

\section{Outcomes}

165 (88\%) patients had a favorable outcome, while 23 (12\%) patients had an unfavorable outcome (Table 3). Stratification of outcome with age, and volume extradural hematoma is given in Tables 4 - 5.

Table 2: Glasgow Outcome Score $(\mathrm{N}=188)$.

\begin{tabular}{|lcc|} 
GOS & Frequency & Percentage \\
$1-3$ & 23 & $12 \%$ \\
$4-5$ & 165 & $88 \%$ \\
Total & $\mathbf{1 8 8}$ & $\mathbf{1 0 0} \%$ \\
Mean GOS: $3 \pm 1.34$ & & \\
\hline
\end{tabular}

Table 3: Outcome $(N=188)$.

\begin{tabular}{|ccc|} 
Outcome & Frequency & Percentage \\
\hline Favorable & 165 & $88 \%$ \\
Unfavorable & 23 & $12 \%$ \\
Total & $\mathbf{1 8 8}$ & $\mathbf{1 0 0 \%}$ \\
\hline
\end{tabular}

Table 4: Stratification of Outcome with Age ( $N=188)$.

\begin{tabular}{lcccccc|} 
Outcome & $\mathbf{2 0 -} \mathbf{3 0}$ Years & $\mathbf{3 1 -} \mathbf{4 0}$ Years & $\mathbf{4 1 - \mathbf { 5 0 }}$ Years & $\mathbf{5 1 - \mathbf { 6 5 }}$ Years & Total & $\mathbf{P}$ value from Chi-Square \\
Favorable & 53 & $\mathbf{4 6}$ & 36 & 30 & 165 & $0.893>0.050$ \\
Unfavorable & 7 & 7 & 5 & 4 & 23 & *Insignificant result \\
Total & $\mathbf{6 0}$ & $\mathbf{5 3}$ & $\mathbf{4 1}$ & $\mathbf{3 4}$ & $\mathbf{1 8 8}$ & \\
\hline
\end{tabular}

\begin{tabular}{|lcccc|}
\hline \multicolumn{5}{|c|}{ Table 5: Stratification of Outcome with Hematoma Volume $(\mathrm{N}=188)}$. \\
Outcome & Small & Large & Total & $\begin{array}{c}\text { P value from } \\
\text { Chi-Square }\end{array}$ \\
Favorable & $\mathbf{( 2 5 - \mathbf { 5 0 }} \mathbf{~} \mathbf{)})$ & $(>\mathbf{5 0} \mathbf{~ m L})$ & 165 & $0.438>0.050$ \\
Unfavorable & $\mathbf{1 2 0}$ & 45 & 165 & ${ }^{*}$ Insignificant \\
Total & 17 & 6 & 23 & result \\
\hline
\end{tabular}

A large biconvex collection of blood under the calvarium highlighting an epidural hematoma is seen in Figure $\mathbf{1}$. Figure 2 shows the axial slice showing epidural hematoma in the frontal region. Figure 3 demonstrates the frontal bone midline fracture on bone window. In Figure 4 compares the pre-operative and post evacuation CT scans of the same hematoma. 


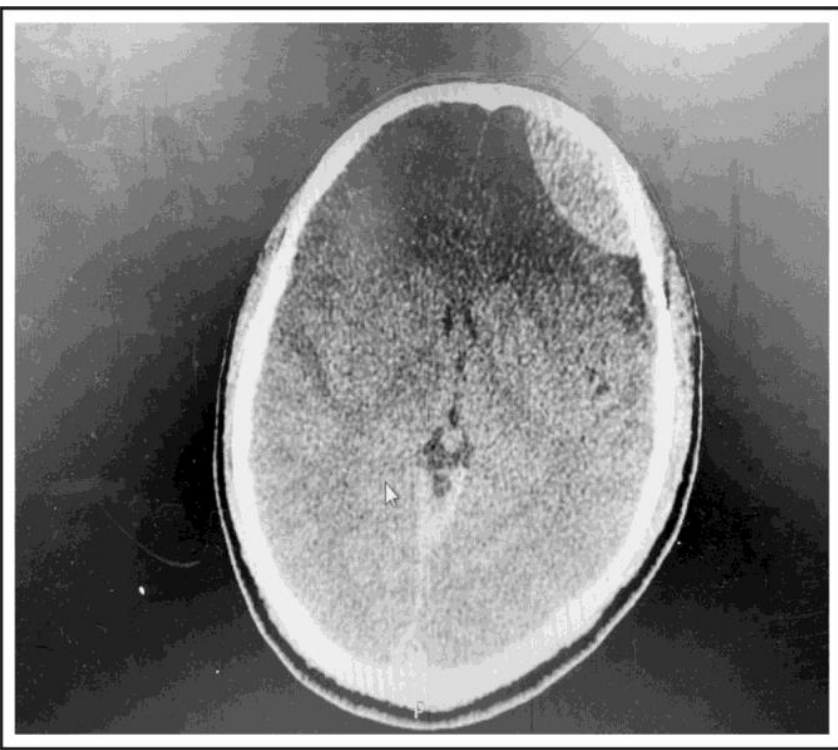

Figure 1: CT scan of an acute left-sided epidural hematoma causing mass effect.

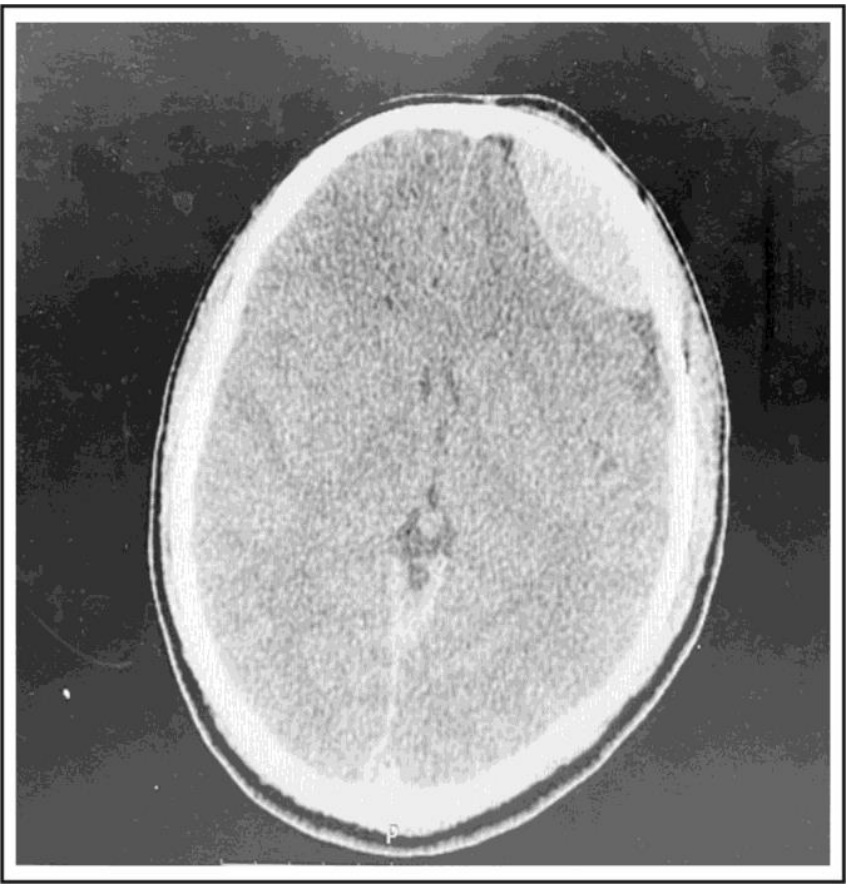

Figure 2: Axial CT scan that demonstrates a large, left frontal epidural hemorrhage $(E D H)$.

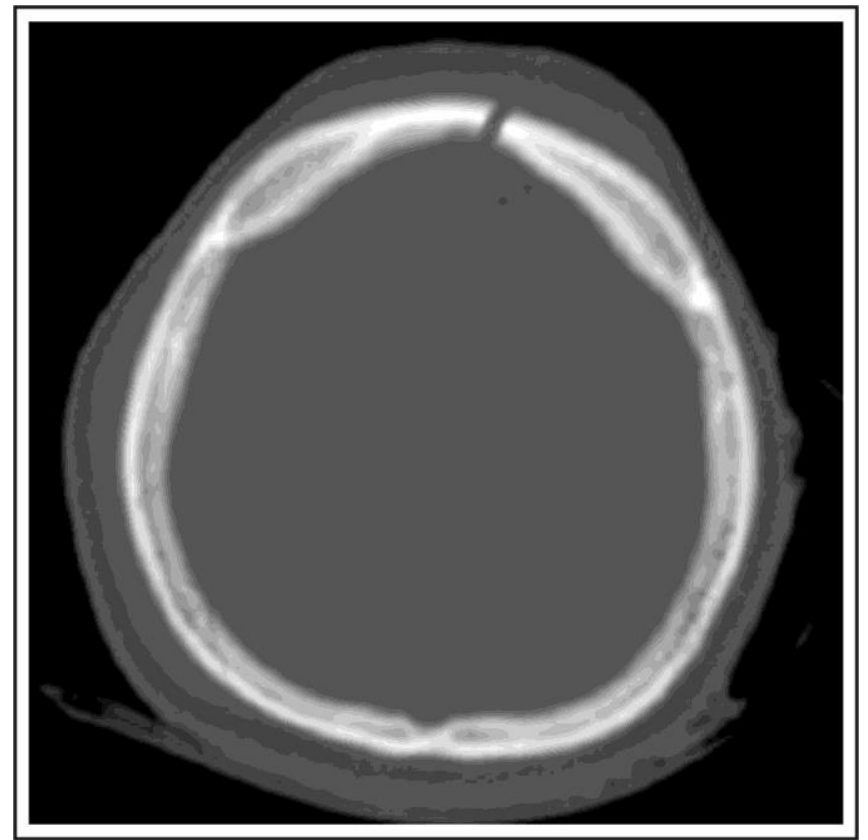

Figure 3: CT bone window image of same patient in demonstrates a large midline fracture.

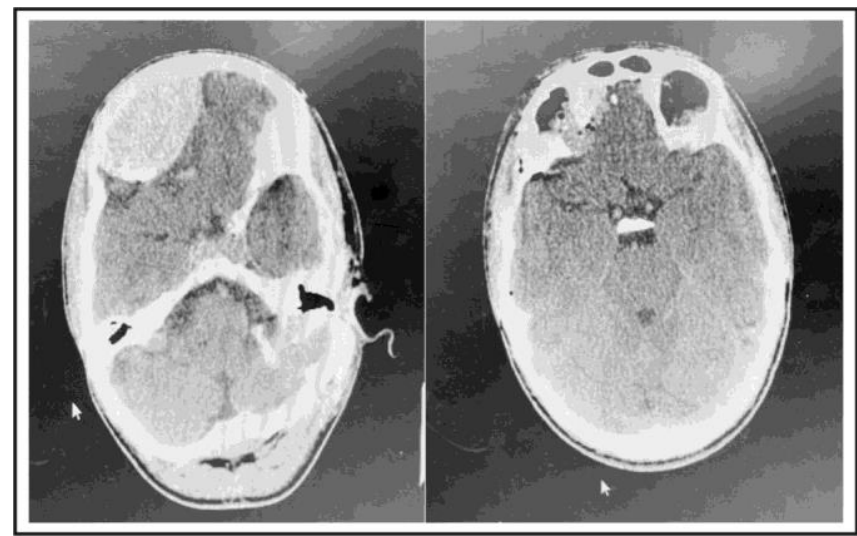

Figure 4: A pre and post-evacuation CT scan of extradural hematoma.

\section{DISCUSSION}

$\mathrm{EDH}$ can have the classic lucid interval in 20 $50 \%$ cases. The patient initially recovers from a sudden unconsciousness after the impact, stays up for a couple of hours, and then falls into deep unconsciousness, owing to an ongoing extradural bleeding and herniation syndrome. ${ }^{23}$ Cushing response occurs in severe hypertension characterized by systemic hypertension, 
bradycardia, and respiratory depression. It occurs when the brainstem gets hypoxic insult. Medication to lower the blood pressure results in further damage and ischemic injury. Surgery alleviates Cushing response ${ }^{24}$. In children, the groove for the middle meningeal artery within the inner table of the skull is not formed and so the incidence of $E D H$ in the temporal region is lower. ${ }^{25} \mathrm{EDH}$ occurs rarely in the vertex or parasagittal areas. ${ }^{26}$ Fishpool et $a{ }_{1}{ }^{27}$ worked out that the middle meningeal artery has two accompanying dural sinuses, therefore the bleeding is mixed with arterial and venous blood. The convex hematoma causes the mass effect, midline shift, and obliterates the ventricle of the same side. Urgent surgical intervention is required. The acute phase is bright/hyperdense on CT scan. At $2-4$ weeks, the density changes to isodense, and later it turns dark (hypodense). Coronal planes are more helpful in viewing vertex hematomas. Associated lesions like subdural hematomas, cerebral contusions, and intracerebral bleeds occur concurrently in $10-$ $50 \%$ of EDH cases. Intubated patients may be ventilated with IMV (Intermittent mandatory Ventilation) at $16-20$ breaths per minute. After performing the craniotomy for $\mathrm{EDH}$, the clots are evacuated. Bleeding vessels are hemostasized, if possible. The dura is inspected. Dura is stitched to the bone. Drains can be placed for 24 hours. Multiple burr holes and negative pressure drainage can also be used for decompression. Endovascular embolization minimizes bleeding in the acute phase. During an emergency and in the absence or unavailability of a neurosurgeon, a burrhole decompression can be performed on the side of the dilated pupil.

The current included 188 patients, who were observed to determine the impact of the volume of extradural hematoma on functional outcome in terms of Glasgow outcome scale and compare the outcome of the small and large size extradural hematoma. Extradural Hematoma $(E D H)$ is a serious complication of head injury.
While the exact incidence is unknown, it is found in $2.7-4 \%$ of traumatic head injury cases. The incidence of EDH is rare in extremes of age; is higher in men as compared to women and is highest among adolescents and young adults. Under 45 years of age, the leading cause of death is head trauma. In almost two-thirds of patients with head injuries, traumatic brain injury is the main cause of protracted disability and/or death. Skull fractures are present in $75-95$ percent of patients. The mortality of EDH varies from $10-$ $40 \%$ and is inversely related to the level of hospital facilities. With early diagnosis and prompt intervention, the mortality from EDH can be reduced thereby improving the outcome in many patients. In this study, $32 \%$ of patients were aged between $20-30$ years, 28\% patients (aged $31-40$ years), 22\% patients (aged $41-50$ years), $18 \%$ patients aged between 51 and 60 years. The mean age is 33 years. Seventy-five percent of patients were male while $25 \%$ of patients were female. Seventy-three percent of patients had extradural hematoma $25-50 \mathrm{~mL}$ while $27 \%$ of patients had extradural hematoma $>50 \mathrm{~mL}$. Twelve percent of patients had GOS scores $1-3$, while 165 (88\%) patients had GOS scores $4-5$. Mean GOS was 3 with SD \pm 1.34 . Eighty-eight percent of patients had favorable outcomes while $12 \%$ of patients had unfavorable outcomes. Mushtaq et al also concluded through their work that outcome in EDH is dependent on the size and volume of the hematoma. $50 \mathrm{~mL}$ to $100 \mathrm{~mL}$ is considered a large volume while $25 \mathrm{~mL}$ to $50 \mathrm{~mL}$ is a small volume. Study of McKissock et al had similar conclusions. ${ }^{28}$ Male to female preponderance of EDH is $4: 1$ as mentioned by Oertal et al. ${ }^{29}$

In our study, the ratio stood at 13:1, as women are usually home-bound. Our study showed that $50 \%$ extradural was formed as a result of road traffic accidents concurring with a study by Servadei et al. ${ }^{30}$ In another series, it was noticed that $40 \%$ patients had no localizing signs or deficits common to head injury patients. 
Teasdale et al, $^{31}$ advocated breaking away from the notion that progressive neurological deterioration is pathognomonic of head injury. Aurangzeb et $\mathrm{al}^{32}$ reported that $57 \%$ of these patients had fallen from a height, 34\% had suffered from road traffic accidents and $8.8 \%$ had been assaulted. Falling from height was seen to occur commonly in patients between 2 and 20 years of age. Road accidents occurred in people with ages in the $10-45$ years range. Assaults were seen in age ranges $28-60$ years, in $6.1 \%$ of the patients. Forty-three percent fractures involved parietal bone, frontal bone in $24.6 \%$, occipital bone in 21.1\%, (20.2\%) patients had fractured temporal bone. Extradural hematoma due to linear skull fracture was seen in $29.8 \%$ of patients. Patients of ages between 2 - 15 years had an extradural hematoma in $23.2 \%$ of linear fractures. Between, $16-35$ years of age its frequency was $40 \%$. Patients in 36-60 years of age had a $36.8 \%$ frequency of $\mathrm{EDH}$, and all patients developed EDH above 60 years of age following the linear skull fractures. Parietal fractures and Extradural hematoma were commonest (48.9\% of patients), temporal bone and EDH occurred in $23.5 \%$ of patients, occipital fractures occurred in $11.7 \%$, and frontal bone fractured in $17.6 \%$ causing $E D H$, in patients. Therefore $73.5 \%$ of extradural hematomas occurred in parieto-temporal regions among the skull and was significantly higher than other bones of the skull.

\section{CONCLUSION}

The volume of extradural hematoma is strongly correlated to the clinical and functional outcome. Prognosis gets worse with the increasing hematoma size.

\section{REFERENCES}

1. Potapov A, Krylov V, Gavrilov A, Kravchuk A, Likhterman L, Petrikov $S$, et al. Guidelines for the management of severe traumatic brain injury. Part 3. Surgical management of severe traumatic brain injury (Options). Zh Vopr Neirokhir Im NN Burdenko. 2016; 80 (2): 93-101.

2. Khaled CN, Raihan M, Chowdhury F, Ashadullah A, Sarkar M, Hossain S. Surgical management of traumatic extradural haematoma: Experiences with 610 patients and prospective analysis. The Indian Journal of Neurotrauma, 2008; 5 (2): 75-9.

3. Cheung PS, Lam JM, Yeung JH, Graham CA, Rainer $\mathrm{TH}$. Outcome of traumatic extradural haematoma in Hong Kong. Injury, 2007; 38 (1): 76-80.

4. Sun DQ, Andresen NS, Gantz BJ. Surgical management of acute facial palsy. Otolaryngologic Clinics of North America, 2018; 51 (6): 1077-92.

5. ur Rehman R, Mushtaq MIUH, Azam F, Khattak A. Skull fracture on $x$-ray skull as an indicator of extradural hematoma in patients with head injury. Pak J Surg. 2012; 28 (2): 106-9.

6. Gerlach R, Dittrich S, Schneider W, Ackermann H, Seifert V, Kieslich M. Traumatic epidural hematomas in children and adolescents: outcome analysis in 39 consecutive unselected cases. Pediatric Emergency Care, 2009; 25 (3): 164-9.

7. Ringl $H$, Schernthaner $R$, Philipp MO, MetzSchimmerl S, Czerny C, Weber $M$, et al. Threedimensional fracture visualisation of multidetector CT of the skull base in trauma patients: comparison of three reconstruction algorithms. European Radiology, 2009; 19 (10): 2416-24.

8. Mishra SS, Nanda N, Deo RC. Extradural hematoma in an infant of 8 months. Journal of Pediatric Neurosciences, 2011; 6 (2): 158.

9. Saatman $K E$, Duhaime $A-C$, Bullock $R$, Maas $A l$, Valadka A, Manley GT. Classification of traumatic brain injury for targeted therapies. Journal of Neurotrauma, 2008; 25 (7): 719-38.

10. Pereira CU, Santos LPA. "Sinal do redemoinho" em hematoma extradural hiperagudo. 2013.

11. McGinn MJ, Povlishock JT. Pathophysiology of traumatic brain injury. Neurosurgery Clinics, 2016; 27 (4): 397-407.

12. Juratli TA, Zang $B$, Litz RJ, Sitoci $K-H$, Aschenbrenner $U$, Gottschlich $B$, et al. Early hemorrhagic progression of traumatic brain contusions: frequency, correlation with coagulation disorders, and patient outcome: a prospective study. Journal of Neurotrauma, 2014; 31 (17): 
$1521-7$.

13. Kinoshita K. Traumatic brain injury: pathophysiology for neurocritical care. Journal of Intensive Care, 2016; 4 (1): 29.

14. Pearn $M L$, Niesman IR, Egawa J, Sawada $A$, Almenar-Queralt $A$, Shah SB, et al. Pathophysiology associated with traumatic brain injury: current treatments and potential novel therapeutics. Cellular and Molecular Neurobiology, 2017; 37 (4): 571-85.

15. Li M, Zhao Z, Yu G, Zhang J. Epidemiology of traumatic brain injury over the world: a systematic review. General medicine: open Access, 2016; 4 (5): e275-e.

16. Peeters $W$, van den Brande $R$, Polinder $S$, Brazinova A, Steyerberg EW, Lingsma HF, et al. Epidemiology of traumatic brain injury in Europe. Acta Neurochirurgica. 2015; 157 (10): 1683-96.

17. Tagliaferri F, Compagnone $C$, Korsic $M$, Servadei $F$, Kraus J. A systematic review of brain injury epidemiology in Europe. Acta Neurochirurgica. 2006; 148 (3): 255-68.

18. Chrousos GA, Cogan DG. Absence of the near reflex in a healthy adolescent. Journal of Pediatric Ophthalmology and Strabismus, 1985; 22 (2): 76-7.

19. Haque ME, Sultana S, Alam MS, Saha K, Begum W. Socio-demographic Characteristics of Extradural Haematoma (EDH) Patients: Expeience of 63 Cases in Bangladesh. Journal of Science Foundation, 2017; 15 (2): 52-6.

20. Rincon S, Gupta R, Ptak T. Imaging of head trauma. Handbook of clinical neurology. 135: Elsevier, 2016: p. 447-77.

21. Marcus EM, Jacobson S. Cerebral Hemispheres: Neuropathology and Clinical Correlation II. NonVascular Syndromes. Integrated Neuroscience: Springer; 2003: p. 597-630.

22. SKULL IT. Regional Injuries. Forensic Medicine and Toxicology.
23. Mauritz W, Brazinova A, Majdan M, Rehorcikova V, Leitgeb J. Deaths due to traumatic brain injury in Austria between 1980 and 2012. Brain Injury, 2014; 28 (8): 1096-101.

24. Sheth K, McCullough M. The Pathophysiology of Intracranial Hypertension and Cerebral Herniation Syndromes. Cerebral Herniation Syndromes and Intracranial Hypertension, 2016: 1.

25. Elgamal EA. Traumatic Brain Injury and Disorders of Intracranial Pressure in Children. Clinical Child Neurology: Springer, 2020: p. 1001-31.

26. Pearl GS. Traumatic neuropathology. Clinics in Laboratory Medicine, 1998; 18 (1): 39-64.

27. McCarthy DP, Donald PF, Scharlemann JP, Buchanan GM, Balmford A, Green JM, et al. Financial costs of meeting global biodiversity conservation targets: current spending and unmet needs. Science, 2012; 338 (6109): 946-9.

28. Mckissock W, Richardson A, Taylor J. Primary intracerebral haemorrhage: a controlled trial of surgical and conservative treatment in 180 unselected cases. The Lancet, 1961; 278 (7196): 221-6.

29. Postuma RB, Berg D, Stern M, Poewe W, Olanow $\mathrm{CW}$, Oertel W, et al. MDS clinical diagnostic criteria for Parkinson's disease. Movement Disorders, 2015; 30 (12): 1591-601.

30. Bullock MR, Chesnut R, Ghajar J, Gordon D, Hartl R, Newell DW, et al. Surgical management of acute subdural hematomas. Neurosurgery, 2006; 58 (suppl_3): S2-16-S2-24.

31. Teasdale G, Jennett B. Assessment of coma and impaired consciousness: a practical scale. The Lancet, 1974; 304 (7872): 81-4.

32. Aurangzeb A, Afridi EA, Khan SA, Muhammad G, Ihsan A, Hussain I, Zadran KK, Bhatti SN. Frequency of extradural haematoma in patients with linear skull fracture. Journal of Ayub Medical College Abbottabad, 2015; 27 (2): 314-7. 


\section{Additional Information}

Disclosures: Authors report no conflict of interest.

Ethical Review Board Approval: The study was conformed to the ethical review board requirements.

Human Subjects: Consent was obtained by all patients/participants in this study.

Conflicts of Interest:

In compliance with the ICMJE uniform disclosure form, all authors declare the following:

Financial Relationships: All authors have declared that they have no financial relationships at present or within the previous three years with any organizations that might have an interest in the submitted work.

Other Relationships: All authors have declared that there are no other relationships or activities that could appear to have influenced the submitted work.

\section{AUTHORS CONTRIBUTIONS}

\begin{tabular}{|l|l|l|}
\hline Sr.\# & Author's Full Name & Intellectual Contribution to Paper in Terms of: \\
\hline 1. & Muhammad Tariq, Muhammad Ali & Study design and methodology. \\
\hline 2. & Mushtaq Ahmad Mian, Muhammad Ali & Paper writing, referencing, and data calculations. \\
\hline 3. & Muhammad Tariq & Data collection and calculations. \\
\hline 4. & Shahid Ayub, Muhammad Tariq & Analysis of data and interpretation of results etc. \\
\hline 5. & Waseem Dad Khan, Muhammad Tariq & Literature review and manuscript writing. \\
\hline 6. & Sohail Daud Khan, Muhammad Tariq & Analysis of data and quality insurer. \\
\hline 7. & Khial Jalal & Literature review. \\
\hline
\end{tabular}

